\title{
Design of the use of chatbot as a virtual assistant in banking services in Indonesia
}

\author{
Bhakti Prabandyo Wicaksono, Amalia Zahra
}

Computer Science Department, Binus Graduate Program - Master of Computer Science, Bina Nusantara University, Jakarta, Indonesia

\begin{tabular}{l}
\hline Article Info \\
\hline Article history: \\
Received Aug 31, 2021 \\
Revised Sep 27, 2021 \\
Accepted Oct 12, 2021 \\
\hline
\end{tabular}

Keywords:

Artificial intelligence

Botika

Chatbot

Rasa

\begin{abstract}
A chatbot is a computer program designed to simulate an interactive communication to user (human) via text, audio, or video. Currently several banks in Indonesia have adopted chat technology in customer service. The application of artificial intelligence in customer service aims to prepare banks for the challenges of industry banking 4.0. In addition, it is also to solve problems currently faced by customer service. Implementing chatbot platform in banking in Indonesia is not just plug and play, although there are quite a lot of chatbot platforms available, including Rasa Platform, Botika Platform, and Kata.ai Platform. However, this study only evaluates two chatbot platforms, namely Rasa and Botika, where the two platforms are considered not yet able to be immediately adopted by banks. This is because the application of banking technology in Indonesia must refer to regulatory regulations, including those related to environmental needs, language, speed, and accuracy to understand the intent of users. Hence, research is needed to decide which chatbot platform can be implemented in the banking industry without violating regulatory regulations. From the results of evaluations conducted using the usability and hedonic motivation system adoption system (HMSAM) methods, it is found that users prefer Botika platform to be implemented in the banking industry.
\end{abstract}

This is an open access article under the $\underline{C C B Y-S A}$ license.

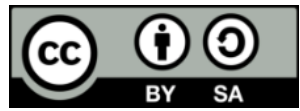

\section{Corresponding Author:}

Amalia Zahra

Department Computer Science, Binus Graduate Program - Master of Computer Science, Bina Nusantara University

Jakarta, Indonesia, 11480

Email: amalia.zahra@binus.edu

\section{INTRODUCTION}

Qwerty Bank is a limited liability company engaged in the financial services industry. Qwerty Bank focuses on the micro, small and medium enterprises (MSME) segment. Currently, it has grown and developed into a bank that has entered the group of medium-sized banks in Indonesia in terms of assets. Along with opening up opportunities and increasing the ability to serve the needs of a wider community, Qwerty Bank has expanded its business to the commercial and consumer segments. These three segments are the business pillars of Qwerty Bank, with services supported by an optimal fund management system, reliable information technology, competence in human resources and good corporate governance practices. This foundation allowed Qwerty Bank to step forward and position it as a credible bank. The operation of Qwerty Bank is currently supported by more than 425 outlets spread across 22 provinces throughout Indonesia which are connected in real time. Qwerty Bank has also built a micro-banking network, which now totals 543 outlets, as part of a partnership program with cooperatives and microfinance institutions.

Customer satisfaction and trust in using bank products and services will be able to attract the interest of prospective new customers [1]. Optimal service certainly provides a positive image for the company 
thereby increasing the company's image in the eyes of customers and prospective customers. One of the roles is done by officers who deal directly with customers, including marketing, customer service and call centers. Functionally, customer service and call center have the same role, namely as a company representative to interact with customers. Broadly speaking, the difference can be seen from the media used to interact, where customer service uses face-to-face media, while the call center uses telephone media.

One of the services provided by Qwerty Bank to customers is call center service. About $50 \%$ of the top 18 customer services are information services. Call Center services have 181 service categories that vary in both banking and credit cards. The services used at Qwerty Bank are using Halo Qwerty 14555 which is managed by a third party where the bank has to pay for such a service based on a fixed scheme every time the number of calls is less than 150,000 . However, if there are more than 150,000 calls per month, the cost will be 2,750 per call.

There is a trend of decreasing number of traffic calls from year to year, but this is not directly proportional to the costs incurred for the Halo Qwerty call center service 14555 every year. One of them can be seen in 2018, the average number of call center services has decreased significantly. When viewed in terms of service, this can be interpreted to be a positive thing for the company, because it indicates the reduction in the number of customer complaints against Qwerty Bank services. However, this is inversely proportional in terms of cost. With an average of 115,776 calls per month, the costs incurred for the call

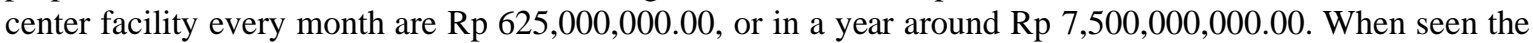
cost per call, it will increasingly look more expensive every year when compared to the cost per call Rp 2,750.00 if the number of calls reaches 150,000 every month. For example, in 2017, the cost per call is Rp 2,750.00, while in 2018 the cost per call will be Rp 5,389.35.

With the increasing use of Chatbot technology, more and more Chatbot platforms are being developed. This can be shown by the large number of information technology (IT) companies that focus their business on the field of Chatbot, such as Kata.ai (https://kata.ai), Rasa Platform (https://rasa.com), Botika (https://botika.online), and so on. However, there is not yet one Chatbot platform that can be adopted and implemented directly by banks in Indonesia. This is due to the fact that the implementation of information technology in the banking industry in Indonesia is required to refer to the regulations issued by the regulator, in this case Bank Indonesia (BI) and the financial services authority or known as Otoritas Jasa Keuangan (OJK). Some of the regulations issued by the regulator include the existence of on-premise obligations. OnPremise simply means that it must manage the infrastructure independently, both hardware, software, network, and so forth. In addition, the regulator also requires that the software used is the property of the Bank and complemented with at least two-factor authentication. Two-factor authentication is a security process where the user provides two means of identification, one of which is usually a physical sign, like a card, and the other is usually something memorized, such as a security code [2]. These things are challenge for banks in Indonesia for adopting Chatbot technology. These challenges are due to the fact that the existing Chatbot platforms can barely be implemented on-premise basis. In addition, most of several existing Chatbot platforms still use English as a knowledge base, thus the language used by the Chatbot platform is still one of the obstacles encountered considering that Indonesian is still the main language of communication in banking in Indonesia.

Based on the explanation above, there are several services in banking that can be replaced by adopting Chatbot technology. This paper outlines a discussion related to the Chatbot platform that can meet the requirements of banking regulators in Indonesia. It can also use Indonesian as a knowledge base, and how the architecture needs to be adjusted to suit the process business and regulations in the bank industry in Indonesia. Additionally, a discussion on the evaluation of Chatbot platforms will also be elaborated and analyzed further.

\section{RESEARCH METHOD}

In a study, a method is needed. This method is used as a reference to get the expected results. The method used to complete this paper is shown in Figure 1.

\subsection{Methodological approach}

A methodological approach is an approach that will be taken to explore the topic. One methodological approach that is commonly used is a literature review. This phase is divided into 2 stages.

\subsubsection{Literature review}

In the literature study stage, it is carried out by collecting and reading writings in the form of articles and journals related to the research topic. Besides that, it can also be done by discussing with subject matter expert. As for the things that are learned including government regulation and Chatbot. 


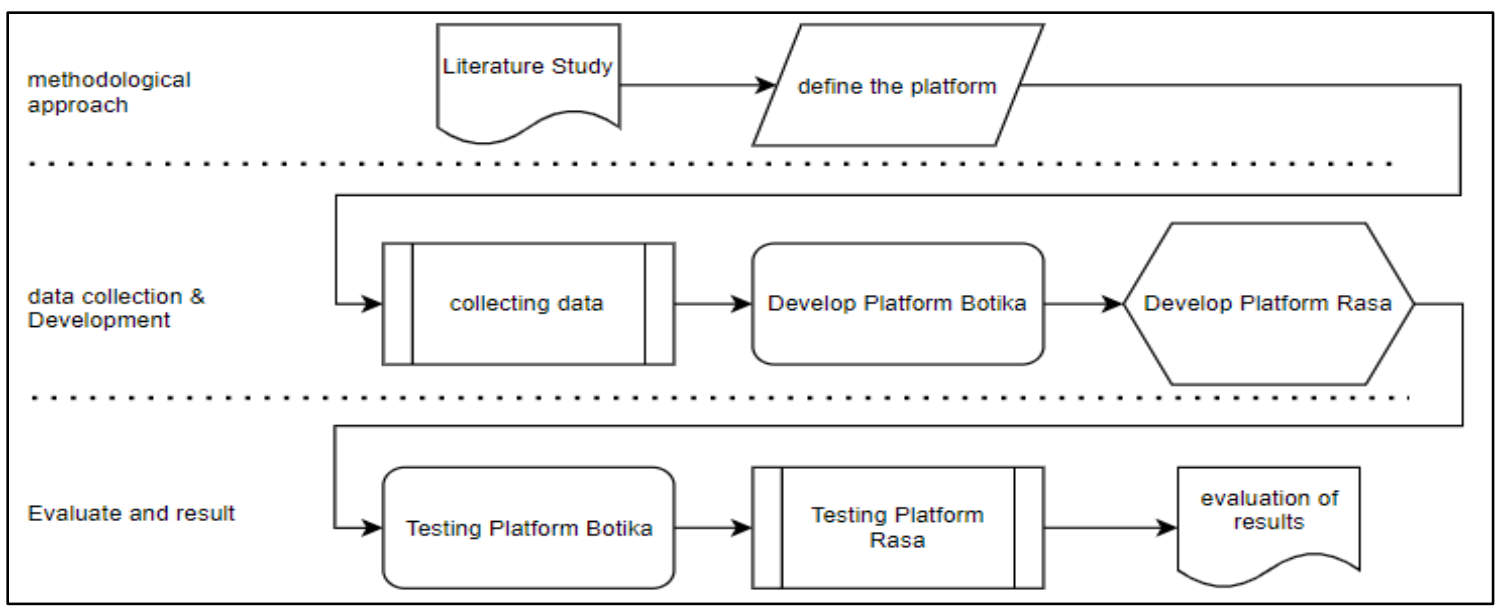

Figure 1. Research method

a. Government regulation

Currently, banks in Indonesia, in carrying out all their activities, must comply with all regulations issued by regulators, namely Bank Indonesia (BI) and the financial services authority Otoritas Jasa Keuangan (OJK). The two regulators, in drafting rules for banking, must refer to other rules defined by the Government of Indonesia. The most recent one is the rules regarding Electronic System and Transaction Management stated in the Government Regulation of the Republic of Indonesia peraturan pemerintah (PP) no. 71/2019. This PP has generally allowed private institutions to use cloud technology. However, it has not been specifically explained what data is allowed.

The latest regulatory rules for the implementation of electronic transactions and systems and digital services in the banking industry are stated in the financial services authority regulation Peraturan Otoritas Jasa Keuangan (POJK) Number 12/POJK.03/2018 concerning the implementation of digital banking services, where the POJK does not refer to PP No. 71 of 2019. Broadly speaking, the POJK still requires every application of digital banking service to use the bank's software with the bank's hardware or the customer's or prospective customer's hardware. Unlike the case with Bank Indonesia Regulation Peraturan Bank Indonesia (PBI) Number 18/40/PBI/2016 concerning the implementation of payment transaction processing. In PBI, every application to be used by a customer or prospective customer must be registered and approved by Bank Indonesia, where in application registration or customer service, it is equipped with several supporting documents, including testing documents (SIT, UAT, and security testing).

\section{b. Chatbot}

Chatbot is a computer program designed to simulate an interactive conversation or communication with the user through text, voice, and visuals. Conversations that occur between computers and humans are a form of response from programs that have been declared in the program database on the computer. The resulting response is the result of scanning keywords in words or sentences from the user and produces the response that is considered the most suitable, or the pattern of words that are considered the closest from the database [3]-[12]. In everyday language, Chatbot is an application or computer program designed to imitate humans themselves. The limitation taken from Chatbot is that it can imitate human communication. Thus, if humans are chatting with the program, it is as if there are two humans communicating with each other. In fact, humans communicate with robots. The robot has been designed to respond to all kinds of questions and statements entered by users. This occurs because it has previously been declared in the database, in the form of word entities, sentence patterns, and various types of statements and questions [13]-[15]. The Chatbot component diagram is shown in Figure 2 [16].

The Chatbot software package consists of three components. The components are being as:

- $\quad$ Responder. The responder is the interface that connects with the user and controls the input made by the user and the output of the replies. Data from responder will be sent to Classifier.

- Classifier. Classifier functions to normalize and filter data sent from users. The data submitted by the user will then be replaced and divided into logical components. The classifier moves normalized sentences into the Graph-master component of the Chatbot. The classifier processes the output of the graph-master component. Apart from that, the classifier also handles database syntax instructions. 
- Graph Master. The Chatbot graph-master component handles matching patterns. Graph-master is responsible for managing content storage or it can be said that Graph-master is the brain of Chatbot. The graph-master also handles the pattern matching process and pattern matching algorithms.

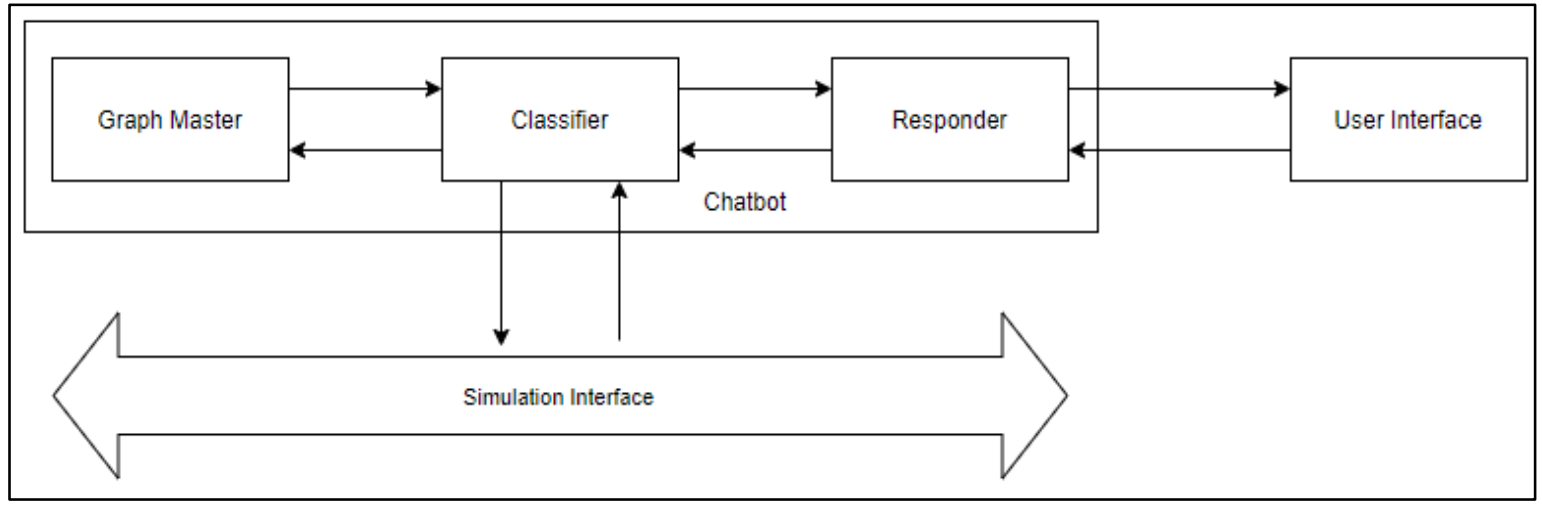

Figure 2. Chatbot component

\subsection{Development}

The development stage is a stage carried out by researchers to explore existing platforms. In this phase, the necessary data is collected and then the data is used to develop applications. There are three stages in this phase, these stages are being as.

\subsubsection{Development of platform botika}

Botika is a startup with a chatbot product or a smart chat assistant that has the task for answering user questions and complaints through the Facebook Messenger, LINE and Telegram chat applications. All messages that come through chat applications connected to Botika can be answered from one place. In addition, Botika can reply to messages for 24 hours using the Indonesian language and provide complete information about the products being sold. Hence, the role of Botika is to replace the role of customer service who has limited time to reply to messages from buyers. Besides making work easier, Botika can also reduce company costs for customer service.

The Botika Platform is a chatbot platform whose environment is in a cloud, so that all conversation data that occurs on the chatbot will later be stored in the cloud for data analytic needs. This is one of the obstacles when implementing the Botika Platform in the banking industry in Indonesia, because the current regulatory regulations do not yet clearly state what data can be stored in the cloud. Develop a Chatbot application on the Botika Platform, user access to a dashboard that can be accessed via https://botika.online is required. After successfully logging into the dashboard, the next steps are creating the following aspects:

- State. State is a setting that defines the position of a Chatbot. Thus, the Chatbot will know after which state it will go to which state.

- Action. Action is a command that is executed by Chatbot in any predefined state where to add commands using the PHP programming language.

- Transition. Transition is used to change the condition of a state with the aim that Chatbot can process or move to another state.

- Integration. The Integration feature functions to integrate the bot into a social media or a web platform to be paired. Botika Platform already provides a feature to facilitate Chatbot integration to the Chat Platform on social media, for example WhatsApp, Facebook, Telegram, and so on. However, this research is only integrated into the webchat which is integrated into the Qwerty Bank corporate web.

- Intent. The Intent feature on the Chatbot functions as a knowledge base, meaning that this feature is used to register questions along with their answers. To register, we can use the bulk method (csv file format) or one by one.

- Train intent. Train intent is a feature on the Botika dashboard. This feature is used to carry out the training data process, after an intent is added, so that it can be recognized by the Bot.

- $\quad$ Test Intent. This feature is used to assure that the data being trained can be recognized by the Chatbot through a string similarity approach. The probability level of a word or sentence delivered can be 
measured from the Test Intents feature. For example, a user submits the word "Halao". The results can be seen in the Figure 3.

In order for the Botika Platform to comply with regulatory regulations, additional development is required on top of the Botika dashboard. This is carried out for features where confidential data is needed, such as card number, identity number, and date of birth. This additional development is carried out by developing a webbased form created using PHP to send the results to a Qwerty Bank server. Afterwards, the Botika Platform will display a link to a form that will open once a customer clicks it. The form can be filled by customers or prospective customers. That way, confidential data will not be sent and stored on the Botika Platform but stored on servers in the Qwerty Bank Data Center.

\begin{tabular}{|c|c|}
\hline ASTRID says & halao \\
\hline Intent & sys.info_greeting \\
\hline Probability & 0.8063 \\
\hline
\end{tabular}

Figure 3. Probability in Botika platform

\subsubsection{Development of rasa platform}

Rasa Core and Rasa natural language understanding (NLU) is an open sources Python library for making conversational software, with the aim of creating machine learning and language understanding based dialogue management that can be developed by non-specialist software developers. Rasa can be developed by environment on premise and using the Python programming language [17]-[23]. The Rasa Platform can be implemented in an on-premises environment but cannot yet be implemented in the banking industry in Indonesia, because the library currently used is spacy version 1.8.2, where this version cannot understand Indonesian perfectly. This is an obstacle when implementing the Rasa Platform. Develop a Chatbot application on the Rasa Platform, several supporting software are needed, including Anaconda3, Python3, Rasa Package version 1.8.1, and Apache. Such software is installed in one environment. The environment used has the specifications of 1 Core, 4 GB RAM, and 100 GB hard disk drive (HDD). After the supporting software are installed, the next steps are:

- Intent. Intent is a question mapping that will be asked to the created a chatbot. The intent will later become the knowledge base for the chatbot application. To describe the intent on the Rasa Platform, it is saved in a file with .yml extension.

- Config. Config is the process of configuring the components needed by the Chatbot. Each configuration is defined in a file and saved in .yml format.

- Action. Action is a file containing programming in Python, where the file is saved in .py format. The action file is a collection of commands that will be executed by Chatbot, where the commands are based on the variables that have been registered in the domain file. The command can be in the form of response text or connect to a service or database.

When viewed from the regulatory perspective, there is no rule violated when implementing the Rasa Platform in the banking industry in Indonesia, because there is no regulation from the regulator that requires applications to use Indonesian. However, the implementation of chatbot using the Rasa Platform is not quite right due to the fact that the majority of the Qwerty Bank's customers are Indonesians, thus it would be more appropriate if the chatbot also uses Indonesian. For this reason, a modification to the Rasa Platform is carried out by replacing or adding relevant Python libraries, for example by adding the natural language toolkit (NLTK) library which is used for natural language processing such as classification, tokenization, stemming, tagging, and parsing. Moreover, a newer version (at least version 2.0) of the Spacy library is used since it already supports Indonesian.

\subsection{Evaluate and result}

In evaluate and result stage, a series of tests were carried out on the system that had been developed previously. This is performed to detect errors early, ensure the system's ability to run, and validate the correctness of the system. After testing is complete, the next step is to evaluate the results.

\subsubsection{Testing platform botika}

This test is carried out using the Blackbox testing method. Blackbox testing is a software testing method that examines application functionality without peering into its internal structure or workings. The results of these tests can be seen in Table 1 . 
Table 1. Test result from Botika Platform

\begin{tabular}{|c|c|c|c|c|c|c|}
\hline Feature & Test Scenario & Step & Data & Expected Results & Result & Pass/Fail \\
\hline Saving & $\begin{array}{l}\text { Show Product } \\
\text { Information }\end{array}$ & $\begin{array}{l}\text { 1. Greeting } \\
\text { 2. Select saving information } \\
\text { 3. Choose "Tabungan" } \\
\text { 4. Savings information: } \\
\text { a. Feature and cost } \\
\text { b. Facility } \\
\text { c. Benefit }\end{array}$ & - & $\begin{array}{c}\text { Information on } \\
\text { Savings Products } \\
\text { Appears } \\
\text { Successfully }\end{array}$ & Success & Pass \\
\hline
\end{tabular}

\subsubsection{Testing rasa platform}

Blackbox testing is also used to perform testing on the Rasa platform. This is done so that the comparison results are comparable to the previous platform. For the Rasa platform test, the test results are as shown in Table 2.

Table 2. Rest result from Rasa Platform

\begin{tabular}{|c|c|c|c|c|c|c|}
\hline Feature & Test Scenario & Step & Data & Expected Results & Result & Pass/Fail \\
\hline $\begin{array}{l}\text { Account } \\
\text { Balance }\end{array}$ & $\begin{array}{l}\text { Display } \\
\text { balance }\end{array}$ & $\begin{array}{l}\text { 1. Greeting } \\
\text { 2. Type "Informasi Saldo" } \\
\text { 3. Type Account Number }\end{array}$ & $\begin{array}{c}\text { Account Number: } \\
4301 * * * * * 987\end{array}$ & $\begin{array}{c}\text { Balance } \\
\text { Information is } \\
\text { Displayed }\end{array}$ & Success & Pass \\
\hline
\end{tabular}

\subsubsection{Evaluation of result}

The evaluation was carried out using the usability method and the hedonic motivation system adoption model (HMSAM) method. Both methods are used to obtain a value, where the value is obtained by giving a questionnaire to at least 15 correspondents with the aim that the results obtained were in accordance with predetermined goals and objectives. Usability consists of three components:

- Think-aloud evaluation (TA). Users are asked to have their opinion and express their feelings when interacting with the application.

- Cognitive walkthrough $(\mathrm{CW})$. The evaluator works through series of task scenarios and asks a number of questions from the user's perspective.

- Heuristic evaluation (HE) is a principle used to evaluate the interaction and interface of a system or application [24], [25].

The HMSAM method is a model for measuring a system that adapts to hedonic motivation [26]. Hedonic motivation refers to the influence of a person's pleasure and pain receptors on their willingness to move towards a goal or away from a threat ${ }^{4}$. There are five factors that are the focus of measurement in HMSAM, namely perceived usefulness, perceived ease of use, curiosity, control, and joy, where these five factors will influence behavioral intention to use and immersion of an application [26]. Thus, HMSAM has five aspects that affect the evaluation results. These aspects are:

- $\quad$ Perceived usefulness, used to measure the increase in performance when using a system.

- $\quad$ Perceived ease of use, used to measure the ease of use of the system.

- Curiosity, used to measure the extent to which a system can increase curiosity in cognitive aspects.

- Control, used to measure the user's perception that he is being invited to interact by the system.

- $\quad$ Joy, used to explore the pleasure aspects of users interacting with the system.

To get the values of each usability and HMSAM component, it is performed by giving a questionnaire to at least 15 correspondents. The questionnaire contains 17 questions. The composition is 
presented in Table 3. Correspondents were asked for their opinion regarding the Chatbot application by providing a choice of categories Strongly Agree (4), Agree (3), Disagree (2), and Strongly Disagree (1) for each question.

Table 3. Composition question usability method and HMSAM method

\begin{tabular}{ccc}
\hline Component & Method & Quantity \\
\hline Think-Aloud Evaluation (TA) & Usability & 5 \\
Cognitive Walkthrough (CW) & Usability & 6 \\
Heuristic Evaluation (HE) & Usability & 6 \\
Perceived ease of use & HMSAM & 4 \\
Perceived usefulness & HMSAM & 3 \\
Curiosity & HMSAM & 4 \\
Control & HMSAM & 4 \\
Joy & HMSAM & 3 \\
\hline
\end{tabular}

\section{RESULTS AND DISCUSSION}

Based on the methodology previously described, this section discusses the results achieved. In terms of application, it produces two Chatbot applications with different platforms. To make the comparison of the two chatbot platforms more comprehensive, assessments obtained from the user's side were also conducted. Two methods were used: usability and the hedonic motivation system adoption model (HMSAM) method. To get the value of each component, a questionnaire method was used. The questionnaire consisted of 17 statements which were asked to 30 respondents. The 17 statements cover the components of the usability method and the HMSAM. Table 4 describes the results of 30 respondents who filled out the questionnaire.

Table 4. Questionnaire results of usability and HMSAM method

\begin{tabular}{ccccccc}
\hline \multirow{2}{*}{ No } & Component & Component of & \multicolumn{2}{c}{ Botika } & \multicolumn{2}{c}{ Rasa } \\
& of Usability & HMSAM & Total & Average & Total & Average \\
\hline 1 & HE & Perceived ease of use & 104 & 3.467 & 93 & 3.1 \\
2 & TA & Perceived ease of use & 99 & 3.3 & 93 & 3.1 \\
3 & HE & Control & 97 & 3.233 & 88 & 2.933 \\
4 & HE & Joy & 92 & 3.067 & 83 & 2.767 \\
5 & CW & Perceived ease of use & 101 & 3.367 & 93 & 3.1 \\
6 & CW & Curiosity & 99 & 3.3 & 88 & 2.933 \\
7 & TA & Perceived ease of use & 98 & 3.267 & 92 & 3.067 \\
8 & HE & Control & 93 & 3.1 & 85 & 2.833 \\
9 & CW & Curiosity & 107 & 3.567 & 99 & 3.3 \\
10 & CW & Joy & 100 & 3.333 & 90 & 3 \\
11 & HE & Perceived usefulness & 92 & 3.067 & 85 & 2.833 \\
12 & TA & Perceived usefulness & 102 & 3.4 & 94 & 3.133 \\
13 & TA & Perceived usefulness & 102 & 3.4 & 96 & 3.2 \\
14 & HE & Control & 96 & 3.2 & 92 & 3.067 \\
15 & TA & Joy & 92 & 3.067 & 89 & 2.967 \\
16 & CW & Control & 89 & 2.967 & 83 & 2.767 \\
17 & CW & Curiosity & 83 & 2.767 & 79 & 2.633 \\
\hline
\end{tabular}

\subsection{Validity and reliability test of the questionnaire}

Whether a research instrument is good or not is determined by its validity and reliability. The validity of the instrument concerns the extent of measurement accuracy in measuring what you want to measure, while reliability questions the extent to which a measurement can be trusted because of its consistency. The instrument is said to be valid if it can reveal data from the variables appropriately not deviating from the actual situation. The instrument is said to be reliable if it can reveal reliable data [27]. In this study, the validity and reliability tests were carried out with the results showing that the $\mathrm{T}$ table value $(5 \%, 30)$ was 1.7 . The data is declared valid because the value of $\mathrm{T}$ count 17 statements is greater than the value of $\mathrm{T}$ table. To perform a reliability test, the variance value, the number of variance and the total variance are needed. The variants are obtained from the var function for all respondents' answers in each statement. The total variance is obtained from the sum of all variance values. After obtaining these three values, then it is used to calculate the reliability value obtained by a value of 0.91 .

\subsection{Usability method}

The results in Table 4 are then grouped by components, which are presented in Table 5. The Total value is obtained from the sum of the average values in Table 4 according to the components, where the 
results of the total column will be divided by the number of questions according to the components, the results of the division are placed in the Average column. From Table 5, user ratings of the two Chatbot platforms prefer the Botika platform to the Rasa platform. This can be proven from the values in the Average and Percentage $(\%)$ columns of the two platforms tested. For the TA component, users rated the Botika platform with a score of $82.15 \%$ better than the Rasa platform which had a value of $77.325 \%$. Furthermore, for the $\mathrm{CW}$ component, the Botika platform has a value of $80.4 \%$ while the Rasa platform has a value of 78.875\%. Finally, for the HE component, users also rated the Botika platform higher with a value of $79.7 \%$ when compared to the Rasa platform which was valued at $73.05 \%$.

Table 5. Result comparison of usability method

\begin{tabular}{ccccccc}
\hline \multirow{2}{*}{ Component of Usability } & \multicolumn{3}{c}{ Botika } & \multicolumn{3}{c}{ Rasa } \\
& Total & Average & Percentage (\%) & Total & Average & Percentage (\%) \\
\hline TA & 16.433 & 3.286 & 82.15 & 15.466 & 3.093 & 77.325 \\
CW & 19.3 & 3.216 & 80.4 & 17.733 & 2.955 & 73.875 \\
HE & 19.133 & 3.188 & 79.7 & 17.533 & 2.922 & 73.05 \\
\hline
\end{tabular}

\subsection{Hedonic motivation system adoption model (HMSAM)}

The results in Table 4 are then grouped by components, which are presented in Table 6. From Table 6 , it can be seen that users judge that the Botika platform has a higher value than the Rasa platform. It can be seen from Table 7 that all the HMSAM components, the Botika platform have a higher value. The Perceived ease of use component of the Botika platform is valued at $83.75 \%$, while the Rasa platform has a value of $77.275 \%$. Furthermore, the perceived usefulness component is valued at $82.2 \%$ for the Botika platform and 76,275 for the Rasa platform. Then, respectively, the curiosity, control, and joy components on the Botika platform compared to the Rasa platform were $80.275 \%$ compared to $73.875 \%, 78.125 \%$ with $72.5 \%$, and $78.875 \%$ compared to $72.775 \%$. From Table 6 , arithmetic calculations are then carried out to get the behavioral intention to use and immersion values as can be seen in Table 7.

Table 6. Result Comparison of HMSAM Method

\begin{tabular}{ccccccc}
\hline \multirow{2}{*}{ HMSAM Component } & \multicolumn{3}{c}{ Botika } & \multicolumn{3}{c}{ Rasa } \\
& Total & Average & Percentage $(\%)$ & Total & Average & Percentage $(\%)$ \\
\hline Perceived Ease of Use & 13.4 & 3.35 & 83.75 & 12.366 & 3.091 & 77.275 \\
Perceived Usefulness & 9.866 & 3.288 & 82.2 & 9.166 & 3.055 & 76.375 \\
Curiosity & 9.633 & 3.211 & 80.275 & 8.866 & 2.955 & 73.875 \\
Control & 12.5 & 3.125 & 78.125 & 11.6 & 2.9 & 72.5 \\
Joy & 9.366 & 3.155 & 78.875 & 8.733 & 2.911 & 72.775 \\
\hline
\end{tabular}

Table 7. HMSAM behavioral invention to use dan immersion

\begin{tabular}{|c|c|c|c|c|c|c|c|c|c|c|}
\hline & \multicolumn{5}{|c|}{ Botika } & \multicolumn{5}{|c|}{ Rasa } \\
\hline & Ease to use & Usefulness & Curiosity & Joy & Control & Ease to use & Usefulness & Curiosity & Joy & Control \\
\hline & 3.35 & 3.288 & 3.211 & 3.155 & 3.125 & 3.091 & 3.055 & 2.955 & 2.911 & 2.9 \\
\hline $\begin{array}{l}\text { Add Perceived ease } \\
\text { to use }\end{array}$ & & 6.638 & 6.561 & 6.505 & 6.475 & & 6.146 & 6.046 & 6.002 & 5.991 \\
\hline $\begin{array}{l}\text { Average Perceived } \\
\text { ease to use }\end{array}$ & & 3.319 & 3.281 & 3.253 & 3.238 & & 3.073 & 3.023 & 3.001 & 2.996 \\
\hline $\begin{array}{c}\text { Total } \\
\text { Average Behavioral }\end{array}$ & & & $\begin{array}{l}.852 \\
.284\end{array}$ & & & & $\begin{array}{r}\text { Behavioral } \\
9 \\
3\end{array}$ & $\begin{array}{l}\text { ntention to } \\
.097 \\
.032\end{array}$ & use & \\
\hline $\begin{array}{l}\text { Percentage } \\
\text { Behavioral }\end{array}$ & & & 82.1 & & & & & 5.808 & & \\
\hline $\begin{array}{c}\text { Total } \\
\text { Average Immersion } \\
\text { Percentage } \\
\text { Immersion }\end{array}$ & & & $\begin{array}{l}.771 \\
.257 \\
1.421\end{array}$ & & & & $\begin{array}{r}\text { Imn } \\
9 \\
3\end{array}$ & $\begin{array}{l}\text { nersion } \\
.020 \\
.007 \\
.163\end{array}$ & & \\
\hline
\end{tabular}

Table 7 shows that the percentage value of Behavioral intention to use is $82.1 \%$ for the Botika Platform and $75.808 \%$ for the Rasa Platform. This value is influenced by the perceived usefulness, curiosity, and joy values. As for the Immersion value, the Botika Platform is higher with a value of $81.421 \%$ compared to the Rasa Platform which is $75.163 \%$. Immersion value is greatly influenced by the curiosity, joy, and 
control components. By looking at the value of the Behavioral intention to use and Immersion components, it means that users will use Chatbot technology more when the Botika Platform is implemented rather than the Rasa Platform which is implemented. The data in Table 8 is then used to measure the significance test, namely "t-Test: two-sample assuming equal variances". The results are shown in Table 9.

a. Hypothesis

- $\quad \mathrm{H} 0: \mu 1=\mu 2$ (There is no significant difference between the mean Botika and Rasa evaluations).

- $\quad H 1: \mu 1>\mu 2$ (There is a significant difference between the mean Botika and Rasa evaluations).

b. Significance Level $(\mathrm{a}=5 \%$ or 0.05$)$.

c. Acceptance criteria

Accept HO if $t$ count=t table or p-value $>$ alpha (a) or Reject H0 If $t$ count $>t$ table or $p$-value=alpha (a).

d. Interpretation of the results of statistical analysis hypothesis test t-test

- $\quad$ Mean is the average value of Botika Output=3.239 and the average value of Rasa Output=2.993.

- Variance is the value of the variation in Botika Output $=0.0054$ and the value of the variation in the Rasa Output $=0.0046$.

- Observations are the number of Botika and Rasa observations, each of which consists of 10 observations.

- $\quad$ Pooled Variance is a combined variation of Botika and Rasa, namely 0.0050.

- Hypothesized Mean Difference is the average difference between Botika and Rasa, but for this case example, it is assumed that there is no difference so that the value is " 0 ".

- $\quad$ df is the Degree of Freedom or degrees of freedom obtained by calculating $n 1+n 2-2$ so that $8+8-2=14$.

- $\quad t$-stat is the value of $t$ count which is equal to 6.951 .

- $\quad t$ critical one tail is $t$ table value that is 1.761 .

- $\quad$ Because the hypothesis shows one direction, namely $\mu 1>\mu 2$ (bigger), then what is seen is only the pvalue and $t$ table ( $t$ critical) in one direction, namely ONE TAIL.

e. Statistical conclusions

- $\quad \mathrm{t}$ count (6.951)>t Table (1.761) means we reject H0 (ACCEPT H1), or

- $\quad$ p-value (3.3743)>alpha (0.05) means we reject H0 (ACCEPT H1).

- $\quad$ Botika is more suitable to be implemented based on the significant differences with the Rasa.

Table 8. Average component HMSAM

\begin{tabular}{cccc}
\hline No & HMSAM Component & Botika & Rasa \\
\hline 1 & Perceived ease of use & 3.35 & 3.091 \\
2 & Perceived usefulness & 3.288 & 3.055 \\
3 & Curiosity & 3.211 & 2.955 \\
4 & Control & 3.125 & 2.9 \\
5 & Joy & 3.155 & 2.911 \\
6 & Behavioral intention to use & 3.284 & 3.032 \\
7 & Immersion & 3.257 & 3.007 \\
8 & All Component & 3.239 & 2.993 \\
\hline
\end{tabular}

Table 9. t-Test: Two-sample assuming equal variances

\begin{tabular}{ccc}
\hline t-Test: Two-Sample Assuming Equal Variances & & \\
\hline & Variable 1 & Variable 2 \\
Mean & 3.238571429 & 2.993 \\
Variance & 0.005415102 & 0.004568857 \\
Observations & 8 & 8 \\
Pooled Variance & 0.00499198 & \\
Hypothesized Mean Difference & 0 & \\
df & 14 & \\
$\mathrm{P}(\mathrm{T}<=\mathrm{t})$ one-tail & 6.95138643 & \\
$\mathrm{t}$ Critical one-tail & $3.37433 \mathrm{E}-06$ & \\
$\mathrm{P}(\mathrm{T}<=\mathrm{t})$ two-tail & 1.761310136 & \\
$\mathrm{t}$ Critical two-tail & $6.74867 \mathrm{E}-06$ & \\
\end{tabular}

\section{CONCLUSION}

The results of the two methods used to test, namely usability and HMSAM on the Botika Platform and Rasa Platform, show that users prefer the Botika Platform from all aspects of testing. These results also provide an overview of the expectations to be achieved in the study. The implementation of Chatbot technology at Qwerty Bank can at least provide new services that make it easier for customers and 
prospective customers. In addition, by obtaining a Chatbot Platform that is suitable for Qwerty Bank, it is hoped that in the future all services at the call center can be implemented so that Qwerty Bank can make savings every month for Call Center fees of Rp 625,000,000.00. In addition, these results can also be used as a reference for banks in Indonesia to implement Chatbot technology in accordance with regulations. In the future, it is hoped that it can assist banking in Indonesia in implementing Chatbot Technology which can be used to provide easy service for its customers. In addition, in the future it is still possible for the Chatbot Platform to be implemented for other features or even replace the customer service and call center as a whole, thereby reducing operational costs. In addition, it can also be used as a platform to support the concept of digital banking and even branchless banking.

\section{REFERENCES}

[1] L. Cui, S. Huang, F. Wei, C. Tan, C. Duan, and M. Zhou, "SuperAgent: a customer service chatbot for e-commerce websites," in Proceedings of ACL 2017, System Demonstrations, 2017, pp. 97-102, doi: 10.18653/v1/p17-4017.

[2] F. Aloul, S. Zahidi and W. El-Hajj, "Two factor authentication using mobile phones," 2009 IEEE/ACS International Conference on Computer Systems and Applications, 2009, pp. 641-644, doi: 10.1109/AICCSA.2009.5069395.

[3] R. Luckin, W. Holmes, M. Griffiths, and L. B. Forcier, Intelligence unleashed: An argument for AI in Education, London: Pearson Education, 2016.

[4] E. S. Khorasani, "Artificial intelligence: structures and strategies for complex problem solving," Scalable Computing: Practice and Experience, vol. 9. no. 3, 2001.

[5] W. Amek, T. Wiegand, and K.-R. Müller, "Explainable artificial intelligence: Understanding, visualizing and interpreting deep learning models," 2019, arXiv:1708.08296.

[6] P. Glauner, J. A. Meira, and R. State, "Machine learning for data-driven smart grid applications," in IEEE Conference on Innovative Smart Grid Technologies, Asia (ISGT Asia 2018), 2018.

[7] X. Zhu and A. B. Goldberg, "Introduction to semi-supervised learning," Synthesis Lectures on Artificial Intelligence and Machine Learning, vol. 3, no. 1, pp. 1-130, 2009, doi: 10.2200/S00196ED1V01Y200906AIM006.

[8] K. Morik, B.-E. Kietz, W. Emde, and S. Wrobel, "Knowledge Acquisition and Machine Learning," United States: Morgan Kaufmann Publishers Inc., 1993.

[9] T. R. Gruber and P. R. Cohen, "Design for acquisition: principles of knowledge-system design to facilitate knowledge acquisition," International Journal of Man-Machine Studies, vol. 26, no. 2, pp. 143-159, 1987, doi: 10.1016/S00207373(87)80088-3.

[10] T. C. W. Lin, "Artificial intelligence, finance, and the law," Fordham Law Review, vol. 88, pp. $531,2019$.

[11] T. Lalwani, S. Bhalotia, A. Pal, S. Bisen, and V. Rathod, "Implementation of a Chatbot System using AI and NLP." International Journal of Innovative Research in Computer Science and Technology (IJIRCST), vol. 6, no. 3, 2013, doi: 10.21276/ijircst.2018.6.3.2.

[12] S. A. Abdul-Kader and J. C. Woods, "Survey on chatbot design techniques in speech conversation systems," International Journal of Advanced Computer Science and Applications (IJACSA), vol. 6, no. 7, 2015, doi: 10.14569/ijacsa.2015.060712.

[13] J. Huang, M. Zhou, and D. Yang, "Extracting chatbot knowledge from online discussion forums," in IJCAI 2007, Proceedings of the 20th International Joint Conference on Artificial Intelligence, 2007, vol. 7, pp. 423-428.

[14] M. Qiu et al., "AliMe chat: A sequence to sequence and rerank based chatbot engine," in Proceedings of the 55th Annual Meeting of the Association for Computational Linguistics, 2017, vol. 2, pp. 498-503, doi: 10.18653/v1/p17-2079.

[15] I. Hwang, H. Jeon, H. R. Oh, D. Lee, M. Kim, and J. Kim "Chatti: a conversational chatbot platform," in Workshops at the ThirtySecond AAAI Conference on Artificial Intelligence, 2018.

[16] D. J. Stoner, L. Ford, and M. Ricci, "Simulating military radio communications using speech recognition and chat-bot technology," The Titan Corporation Orlando, 2004.

[17] T. Bocklisch, J. Faulkner, N. Pawlowski, and A. Nichol, "Rasa: open source language understanding and dialogue management," 2017, arXiv:1712.05181.

[18] A. Conneau, H. Schwenk, L. Barrault, and Y. Lecun, "Very deep convolutional networks for natural language processing," 2016, arXiv: 1606.01781 .

[19] W. Yin, K. Kann, M. Yu, and H. Schütze, "Comparative study of cnn and rnn for natural language processing," 2017, arXiv:1702.01923.

[20] M. F. McTear and Z. Callejas, Voice application development for Android, Packt Publishing, 2013.

[21] B. Swartout and Y. Gil, "EXPECT: Explicit Representations for Flexible Acquisition," in Proceedings of the Ninth Knowledge Acquisition forKnowledge-Based Systems Workshop (KAW'95), 1995.

[22] A. Radford, K. Narasimhan, T. Salimans, and I. Sutskever, "Improving language understanding by generative pre-training," pp. 2$12,2018$.

[23] D. Braun, A. H. Mendez, F. Mathhes, and M. Langen, "Evaluating natural language understanding services for conversational question answering systems," in Proceedings of the 18th Annual SIGdial Meeting on Discourse and Dialogue, 2017, pp. 174-185, doi: $10.18653 / \mathrm{v} 1 / \mathrm{W} 17-5522$

[24] D. Quiñones, C. Rusu, and V. Rusu, "A methodology to develop usability/user experience heuristics," Computer Standards and Interfaces, vol. 59, pp. 109-129, 2018, doi: 10.1016/j.csi.2018.03.002.

[25] J. Axup, S. Viller and N. J. Bidwell, "Usability of a mobile, group communication prototype while rendezvousing," Proceedings of the 2005 International Symposium on Collaborative Technologies and Systems, 2005, pp. 24-31, doi: 10.1109/ISCST.2005.1553290.

[26] P. B. Lowry, J. E. Gaskin, N. Twyman, B. Hammer, T. L. Roberts, “Taking 'fun and games' seriously: proposing the hedonicmotivation system adoption model (HMSAM)," Journal of the Association for Information Systems, vol. 14, no. 11, pp. 617-671, 2012, doi: 10.17705/1jais.00347.

Int J Artif Intell, Vol. 11, No. 1, March 2022: 23-33 
[27] M. Lacity, A. Yan, and S. Khan, "Review of 23 years of empirical research on information technology outsourcing decisions and outcomes," Proceedings of the 50th Hawaii International Conference on System Sciences, 2017, doi: 10.24251/HICSS.2017.632.

\section{BIOGRAPHIES OF AUTHORS}

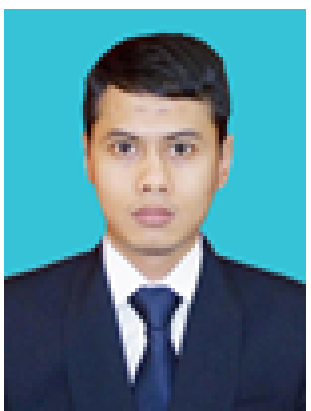

Bhakti Prabandyo Wicaksono (iD) 81 SC P currently holds a Bachelor of Engineering degree obtained from the Muhammadiyah University of Jakarta in 2012. He started his IT career in the Banking Industry in 2013, until starting in 2019 he was trusted to be the AVP IT Department to head the Digital Platforms and Data Analytics. Currently he is a graduate student at Master of Computer Science in Bina Nusantara University. His research is in the area of natural language processing (NLP). He can be contacted at email: bhakti.wicaksono@binus.ac.id.

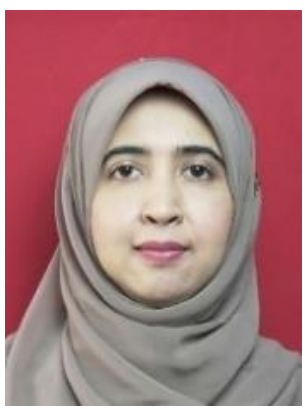

Amalia Zahra (D) 8. SC P is a lecturer at the Master of Information Technology, Bina Nusantara University, Indonesia. She received her bachelor's degree in computer science from the Faculty of Computer Science, University of Indonesia (UI) in 2008. She does not have a master's degree. Her Ph.D. was obtained from the School of Computer Science and Informatics, University College Dublin (UCD), Ireland in 2014. Her research interests cover various fields in speech technology, such as speech recognition, spoken language identification, speaker verification, speech emotion recognition, and so on. Additionally, she also has interest in natural language processing (NLP), computational linguistics, machine learning, and artificial intelligence. She can be contacted at email: amalia.zahra@binus.edu. 